\title{
AUGMENTED REALITY IN GREETING CARDS
}

by

Rayhane Mobaseri

Bachelor of Arts in Arts Administration, Bishops University, 2017

Bachelor of Fine Arts in Painting,

University of Science and Culture, 2014

\author{
A Major Research Paper \\ presented to Ryerson University
}

in partial fulfillment of the requirements

for the degree of

Master of Digital Media

in the Program of Digital Media

Toronto, Ontario, Canada, 2019

(C) Rayhane Mobaseri, 2019 


\section{AUTHOR'S DECLARATION FOR ELECTRONIC SUBMISSION OF A MRP}

I hereby declare that I am the sole author of this MRP. This is a true copy of the MRP, including any required final revisions.

I authorize Ryerson University to lend this MRP to other institutions or individuals for the purpose of scholarly research.

I further authorize Ryerson University to reproduce this MRP by photocopying or by other means, in total or in part, at the request of other institutions or individuals for the purpose of scholarly research.

I understand that my MRP may be made electronically available to the public.

Rayhane Mobaseri 


\author{
Abstract \\ AUGMENTED REALITY IN GREETING CARDS \\ Rayhane Mobaseri \\ Master of Digital Media \\ Digital Media \\ Ryerson University, 2019
}

The concept I have been exploring is a mobile app for greeting cards integrated with augmented reality. The idea is to create modernized forms of sharing messages to loved ones through personalized designs created by a variety of independent artists. The product will be greeting cards illustrated by young and/or independent artists that have a personalized AR element, activated through the app. The AR element, is linked to an animated component in relation to the original illustration, or it can be customized by a clip uploaded by the user for a more personal touch. The app is divided into two sections, activating a ready made card, or customizing and creating your own card and ordering a physical copy or sharing it on online platforms. The overall hope for the product is to offer a personalized form of interactivity within greeting cards which hasn't existed previously or explored as thoroughly. 


\section{Acknowledgments}

Throughout this project and paper I have received a great deal of support and guidance from my supervisor, Professor Alex Ferworn, you have my sincere gratitude. I would also like to thank Professor Steven Cober, who supported and inspired me greatly as a second reader.

I would like to acknowledge the faculty and staff of the MDM program for creating a supportive and rewarding academic experience, and also my family who never stopped believing in me.

Finally, I would like to thank and express my love for my fellow MDM candidates who have inspired me to be the best I can be. Your friendship has been the highlight of the program, and I appreciate each and everyone of you. 


\section{Table of Contents}

Author's Declaration $\quad$ ii

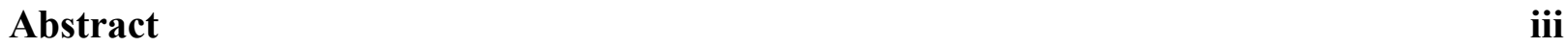

Acknowledgements $\quad$ iv

Table of Contents $\quad$ v

$\begin{array}{lc}\text { List of Figures } & \text { vi }\end{array}$

1. Introduction $\quad 1$

1.1 What are Greeting Cards 1

1.2 The Culture of Greeting Cards 1

1.3 The Creative Changes 2

2. Literature Review $\quad 3$

2.1 The Greeting Card Industry 3

2.2 Augmented Reality and Business Integration 4

3. Project Concept $\quad 5$

3.1 Idea Development 5

3.2 Business Mandate and Expansion $\quad 10$

4. Conclusion and Future Work 11 


\section{List of Figures}

Figure 1. Traditional Card and AR Card Comparison

Figure 2. Idea Development Process

Figure 3. First UI Sketch

Figure 4. Final UI Design

Figure 5. Final UI Design, Customization

Figure 6. Final UI Design, Library, Ordering and Sharing 


\section{Introduction}

\subsection{What are Greeting Cards?}

Greeting cards have social meanings, they prove that commodities can be identified as gifts due to the process of choosing and shopping for them, adding a personal touch, and attaching sentiment. This means the steps taken to select and purchase a greeting card, sends a message of appreciation and kindness to the receiver, making the experience about more than simply buying a product.

\subsection{The Culture of Greeting Cards}

The oldest history of greeting cards goes back to ancient China and Egypt ("Greeting Cards Trends", 2018). By the 1850s they turned into popular and common means of personal communication instead of expensive, handmade gifts (“Greeting Cards Trends", 2018).

Victorians took these creations to a different level, making them into art forms like how they did so with the art of the chocolate box which adorned flourishing blooms, entwined hearts and cherubic, and bonneted children ("Greeting Cards Trends", 2018).

The greetings card industry has boomed in the past few years due to the recent innovations in the sector, and millennials buying more greeting cards. With millennials using Facebook, Snapchat and the other social platforms, the need for a physical outlet has increased. This has encouraged the creative minds to find new and fun ways to create and sell greeting cards. 


\subsection{The Creative Changes}

The recent trends in greeting cards have increased the consumer demand, specifically amongst millennials. As people are looking for more engaging and fun solutions, the main design element in the new generation of greeting cards has been the presence of an interactive component. The secondary element is the ability to customize and personalize the cards, to add a more personal touch and separate them from the generic, mass-produced, store-bought cards.

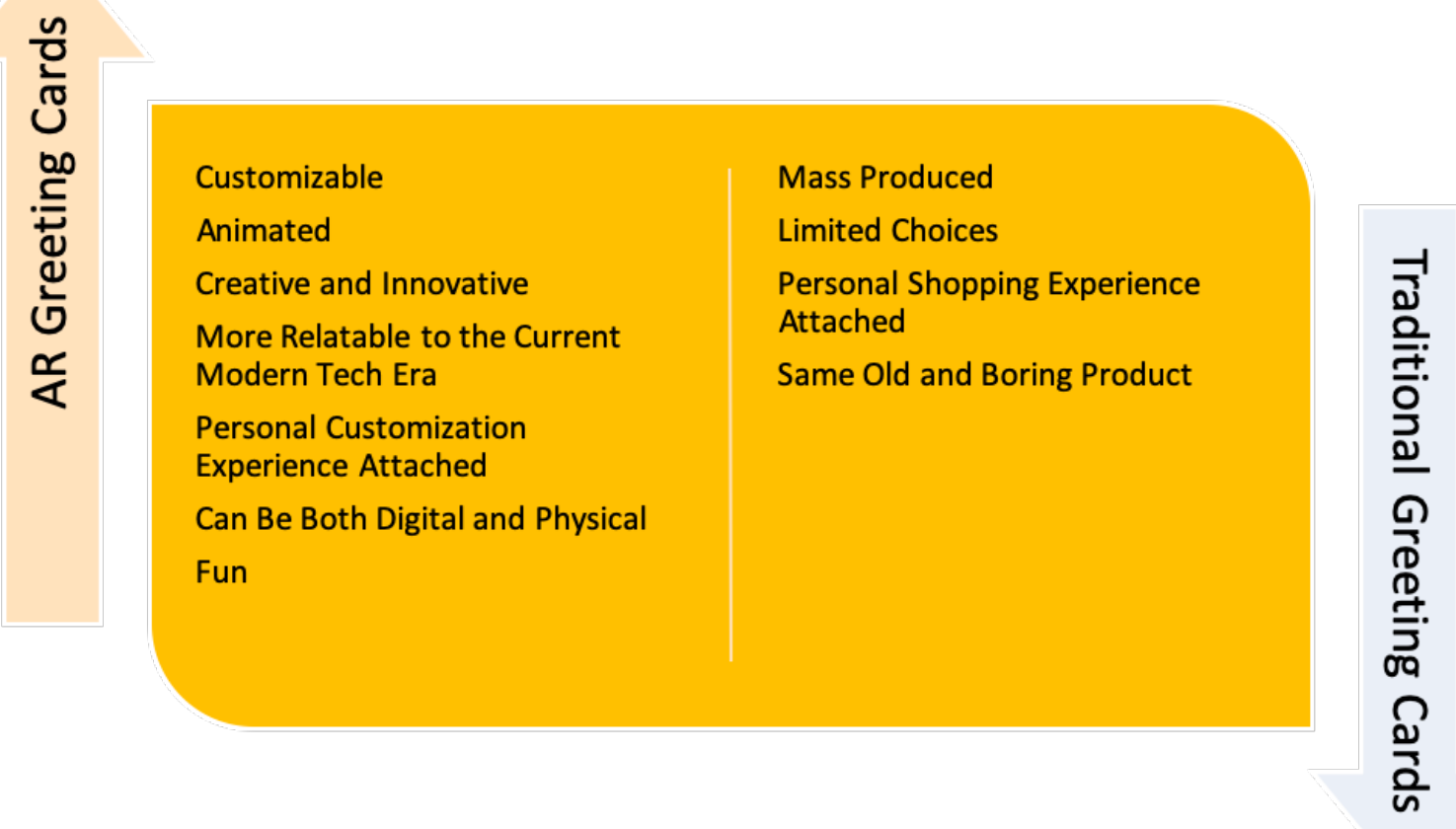

Figure 1. Traditional Card and AR Card Comparison

Some of the new innovations are pop up greeting cards, where as you open the card, the paper made component pops up and creates a fun and happy experience. There is also LED integrated greeting cards, adding the element of light to create a more interesting and unique 
card, which I believe is the next level of the older musical cards. The demand for hand-painted greeting cards has also increased, as it makes it more personalized and it is more valued, due to the original one-of-a-kind artwork that is illustrated by the artist. Although it should be mentioned, that the occasional high cost for these cards has been effecting the overall purchase quantity.

\section{Literature Review}

\subsection{The Greeting Card Industry}

"Over the past year, greeting card revenue has been steady. The greeting card industry could bring in as much as $\$ 933$ million this Valentine's Day, up a bit from last year's estimated \$894 million, according to the National Retail Federation” (Bhojwani, 2019).

Before the innovations in the sector, the industry believed that the mass production of greeting cards lacked personalization. You can see the difference between machine made card products and the traditional off the shelf cards (Jaffe, 2019). This is a good example of how the figurative virtual element can be conjured into literal representation by using augmented reality tools.

"I have sent my husband anniversary cards through the mail. In doing so, I create an event, a virtual interaction with me at the moment he finds and opens the card. In doing so, I engage a fiction - that I am sending it to him from afar, which in our case, is bound to make him think of a period in our courtship when we were separated and frequently wrote and sent cards. If I were there in person, I could refer to that period and our 
feelings ('Do you remember when ... ?'), but with the card, I recreate the context of that feeling" (Jaffe, 2019).

After researching innovative greeting cards, I found a company that is creating AR based greeting cards called Kineticards. Their idea achieved success mainly due to their use of vivid colours, their card illustrations, and detailed animations created for each card. The company's creative director, Chrissy Eckman has been encouraging personalized cards, and she also invites artists for creative collaborations with the company.

\subsection{Augmented Reality and Business Integration}

Augmented reality (AR) is an interactive technology that changes the physical space surrounding the user by adding virtual media components such as animations, images, videos and sounds. The most relevant media characteristics of augmented reality as stated in these definitions are the following: interactivity, virtuality (presence of elements of virtual reality), geolocation feature / location specificity, mobility (in terms of portability and wear ability) and synchronization of virtual and physical/real (augmentation) (Javornik, 2016).

The first and main benefit of using AR integration in a product of business, is the impact it has on user engagement; it creates an almost life like experience that results in customer satisfaction. As customer satisfaction increases, so does customer loyalty. The second benefit is the accessibility, especially when it comes to handheld devices such as phones and tablets, by cutting the cost and space of VR/AR equipment. It allows the user to have an easy and affordable platform to use for AR and VR contents. The third benefit is the uniqueness AR offers, as it 
allows companies to stand out within the market by creating an unlimited range of products and services. Since AR elements are digital, there is no capacity limit for information, so one marker can store a lot of content, media, and data which is linked to it.

"While consumer responses can become more intense with higher media richness, a presence of narration, cause-effect and storytelling in virtual and augmented reality experience reveals even stronger impact on consumer ROI, playfulness and perception of service quality in comparison to rich media without narrative elements (Huang \& Hsu Liu, 2014).However, a study by Kim and Lennon (2008) presented contrary findings, i.e. that effects of online verbal representation as opposed to the visual one were found to have a stronger impact on brand knowledge, attitude and purchase intentions. Also, Goel and Prokopec (2008) showed that despite the fact that virtual worlds offer a richer media, websites are significantly better in establishing trust, informativeness and product diagnostically, as they offer more information" (Javornik, 2016).

\section{Project Concept}

\subsection{Idea Development}

The idea came to me as a way to develop my personal skills, over the past year I have been working on my digital art development skills since creating content digitally is trending today. After attending an Augmented Reality (AR) course in the winter semester and learning how difficult it was, I decided to take it head on challenging myself to complete it. I decided combining something I love doing, digital illustration, and something I would like to learn and add to my skill set, augmented reality. 


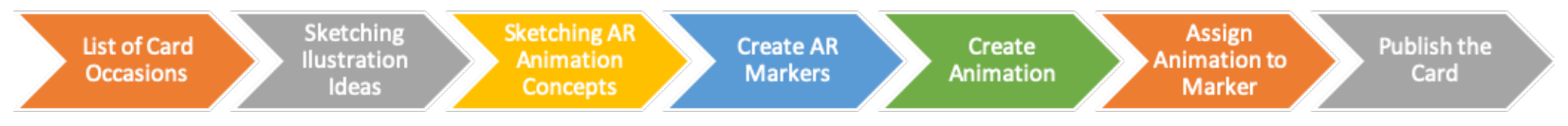

Figure 2. Idea Development Process

The project concept is a mobile app for augmented reality integrated greeting cards. In a bigger picture, there will be greeting cards illustrated by young artists which will have AR elements activated through the app. While the project continues moving forward, I am hoping to add various sensor elements to make it interactive. Such interactions can include being able to blow out virtual candles on a virtual cake through the device's microphone.
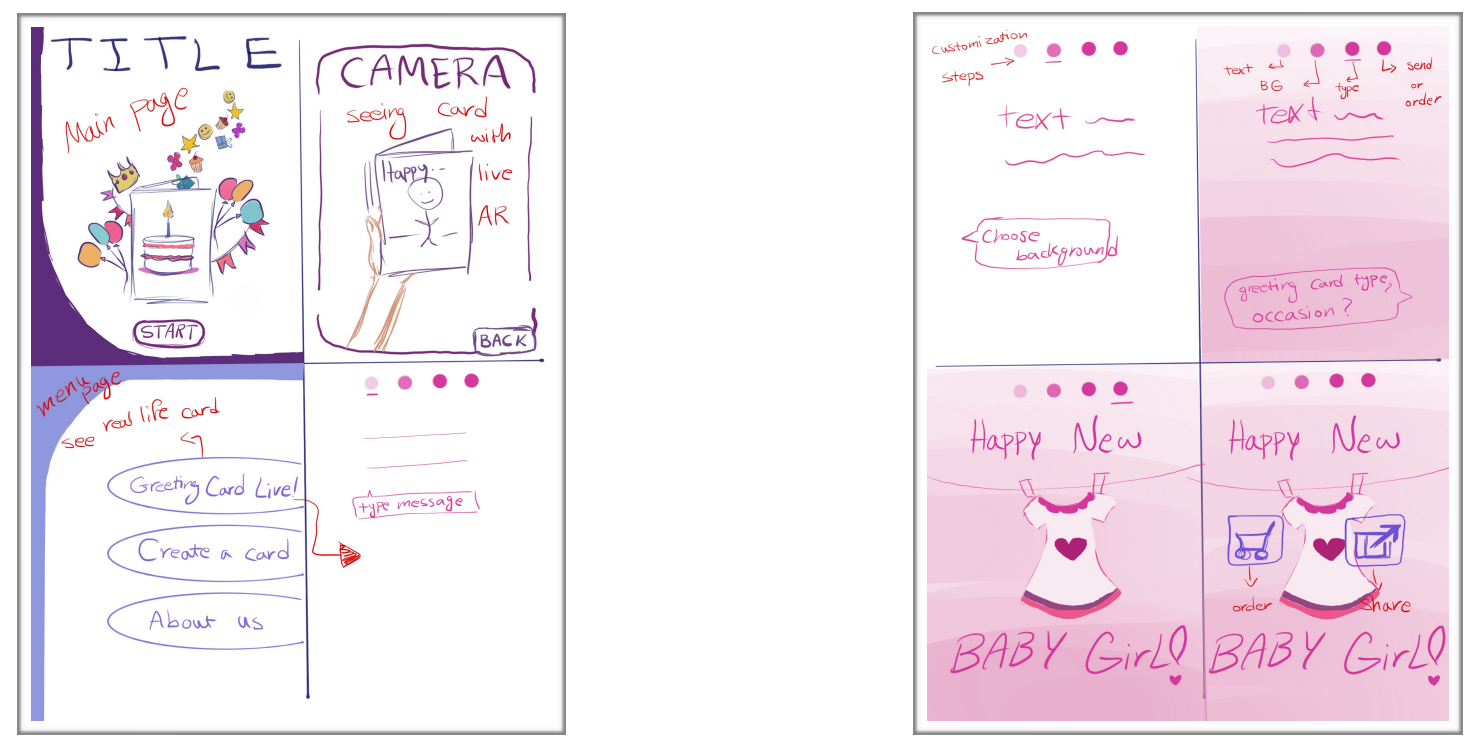

Figure 3. First UI Sketch

The app is called Animate Cards! The ultimate goal for this product is to make a fun and interactive platform that evokes emotion and offers a virtual connection between users. The product will offer a unique way to enjoy augmented reality and offer anyone with a smartphone a creative alternative to the traditional greeting card. Finally you can get your kids a card they can play and create a memory with that will last forever. 
I designed the first UI sketch using Procreate app on iPad, aiming to be simple, bold, and user friendly. I switched to a bright colour palette with two complimentary colours of yellow/ orange and navy for the final prototype. The different section transition is easily attainable with swipe features. For the final prototype, I illustrated a birthday greeting card, with an AR element, adding motion graphics. The UI design was created using Adobe XD. The app has two main sections: 1. Viewing a tangible card with AR marker or 2. Creating your own customized digital card. An individual uses the handheld device camera to detect the marker on the card and activate the AR element attached to it.

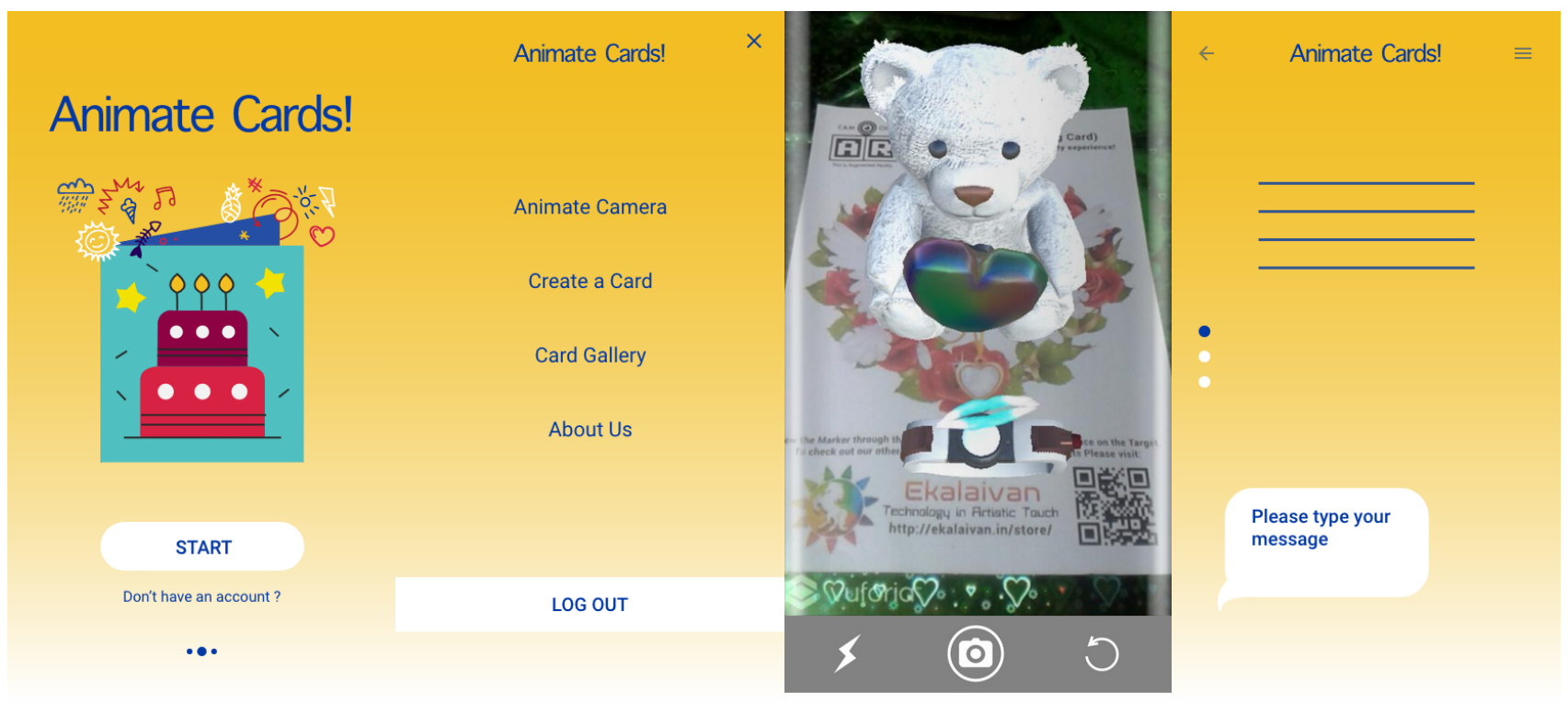

Figure 4. Final UI Design

The second option allows the user to create their own personalized digital card in a few steps by choosing their message, by typing in the desired message for their loved ones. The background, which offers a list of different images to choose from created by the artists. The card occasion which contains an animated AR element related to that topic. And finally sharing it through social media, email, etc or purchasing a physical copy to be delivered to the customer. 
The AR element in my original concept, which is the current prototype, was creating animated illustrations, or loop clips, but as the idea progressed, I decided to expand to different options. Other than using animation elements, I propose integrating ten to thirty second video clips provided by the client for the customizable cards. Imagine you have a video clip of your child's first steps, so you can re-live that moment simply by pointing your camera to your card and see it come to life again. No need to save the video clips on your phone as it adds a more unique and life-like aspect.
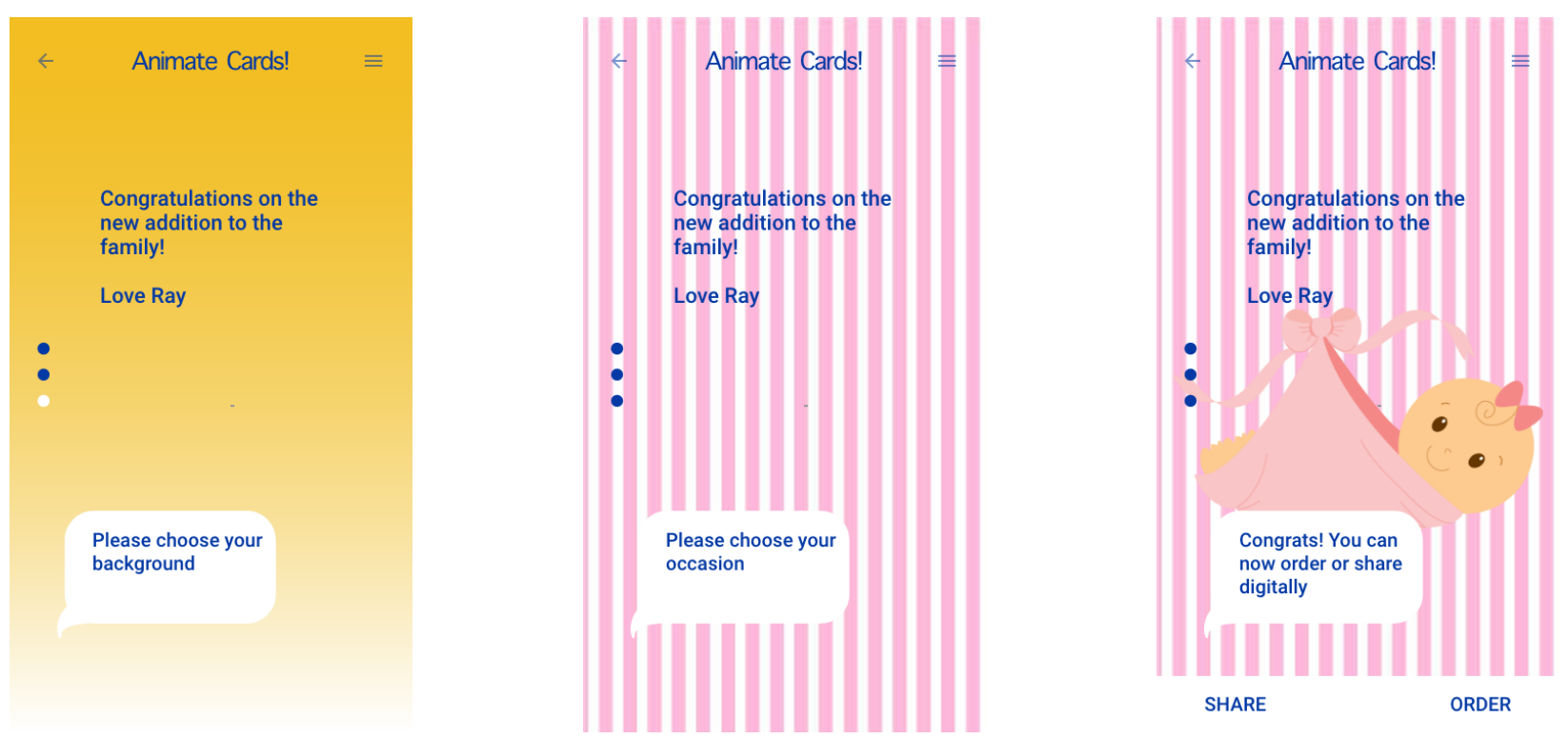

Figure 5. Final UI Design, Customization

Another feature we would offer, would be to sell AR markers as some users choose to create their own greeting cards or have a previously purchased or created card they may want to still use. Since AR allows for unlimited capacity of data, we can add a marker based on their cards and give the option for them to purchase it with their digital content attached. For example, a client makes a DIY wedding anniversary card. She has a clip of a happy memory from each year with her other half. She can send the clips to us and we will integrate them all within a 
single marker, and every year thereafter she can just add another clip to the same marker which will save her time and money.

The app also contains a Cloud library. As the user animates the card with our application, they have the option to save the clip in their library. This allows the user to easily save the animations and clips, and it also works well if the card was gifted by someone and has an integrated clip where the user is not the original clip owner.
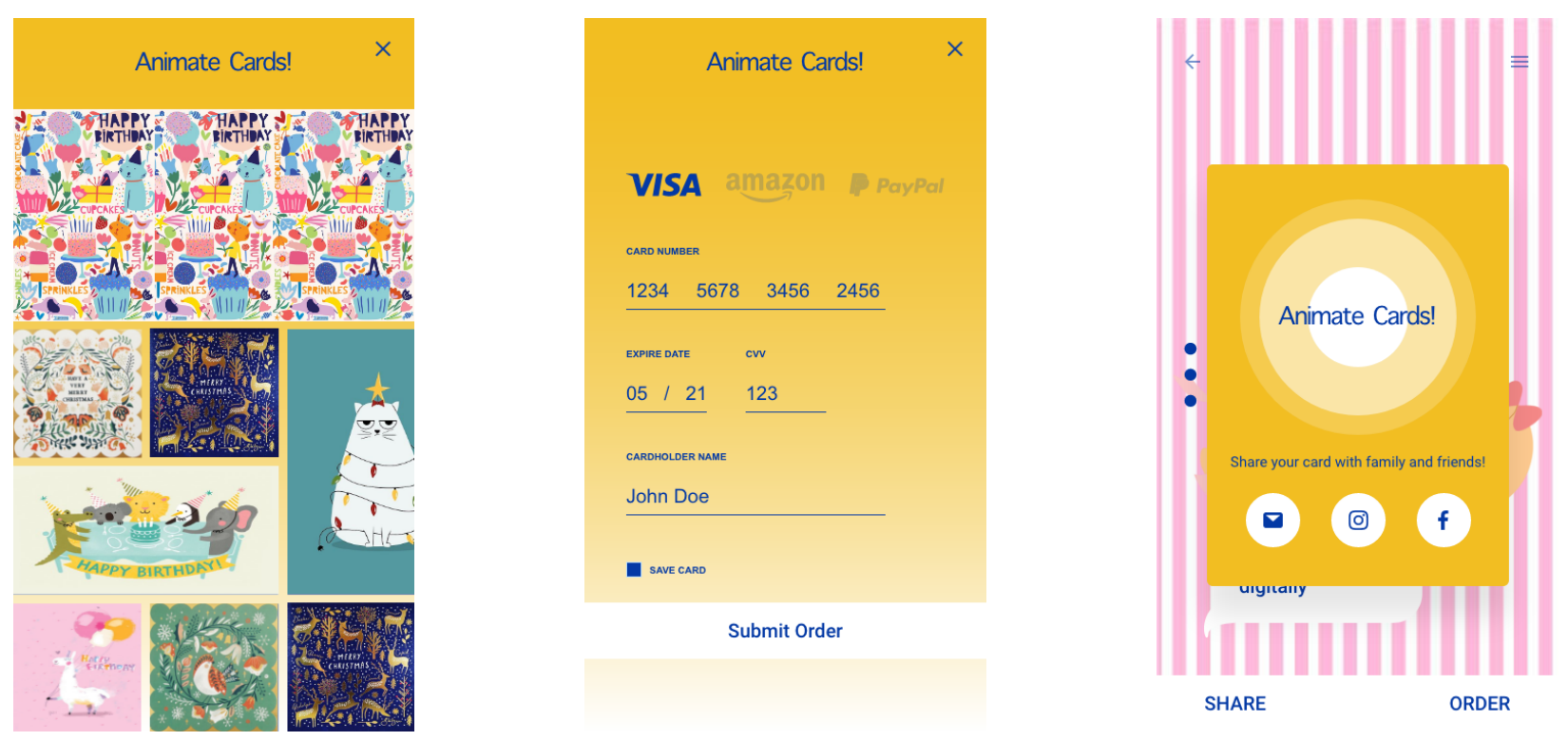

Figure 6. Final UI Design, Library, Ordering and Sharing

After the initial UI design, I created a thirty second animation using the birthday cake illustration made on the main page of the app, which is also the marker for the AR clip event. This was created using Adobe Animate CC. To achieve a functional app prototype, I imported the images and clip to different scenes on Unity, by using the UI tools on the program. I created six main scenes demonstrating how the app works. 


\subsection{Business Mandate and Expansion}

Animate Cards! in the future will be an AR integration and motion graphic studio. The company values are about encouraging creativity and innovative thinking, by increasing creative job opportunities and introducing creative products and services to the community. We will help change the political field within the arts, to one which promotes innovative work and collaboration. Furthermore, we will secure sponsors who share the same values of supporting upand-coming artists through both exposure and fair pay.

As I explained, within the existing company Kineticards, the concept of collaboration played a big part in my idea and company concept. The greeting cards application will be a small branch of what a product example could be. The interactive content creators will be students or recent graduates who are entering a variety of work fields, such as design, arts, engineering and computer science. The diversity of fields creates accessible content that can reach a wide range of users. This interdisciplinary approach results in creative and unbiased content that might even find solutions to existing problems. This can be an educational experience for the creators and the users. Artists need to incorporate technology in their creations to meet the needs of current users.

My point of view on using student resources, is that it helps them develop and improve their creative skills, teamwork, and bringing their ideas to life to benefit themselves and contribute to the community they are a member of. This is to achieve:

- Helping young artists recognize and improve their strengths and learn new skills

- Encouraging the industry to hire more entry level artists and recent graduates 
- Supporting working artists to defend their rights, articulate their needs and celebrate their accomplishments

- Increase international and local collaborations and as a result creating a more diverse and cultured community

The company will create different income opportunities to support the operation and salary expenses. For example when the platform becomes successful, we can charge professional and more well known artists for a fee to use the space for selling their card creations in collaboration with us. Another way is using government sponsorship and funding, as the company is hiring graduate students and young artists, it helps the government with low employment rates of recent graduates in the society. We can also use ads or collaboration with other private companies. For example we can collaborate with Starbucks by displaying their advertisements or creating AR integrated Starbucks gift cards.

\section{Conclusion and Future Work}

Other ideas to expand this line of AR integrated products and services in the future can include, but not be limited to the following: 1) For more professional approach, the idea of AR integrated greeting cards can be an effective product. As an example, a graphic designer can have a simple minimalist designed business card but with an AR marker that can showcase some of their portfolio content to their potential client. This content can be added, deleted and edited at any time and saves them time and money. It also helps them stand out and make a good first impression. 2) For educational purposes, AR integrated books, which already exist, and flash 
cards. This helps make the learning experience more fun and interactive for the user, especially when it is used with a younger audience.

As the entertainment industry continues to incorporate AR into their marketing, we can utilize their usage for other business opportunities. For example, AR markers for movie posters and movie tickets. This idea came to me after seeing Spider-Man Into the Spider-Verse AR content which was accessible through a web browser. You can have animated logos on the ticket, or characters coming to life from the posters. Additionally, for entertainment purposes we can use AR integration for game boards or game cards such as Magic the Gathering or Dungeons and Dragons, and this can liven up the physical content. For Dungeons and Dragons, there can be digital content for a character's weapons, where one can get a more detailed view, being able to rotate the weapon or see a three-dimensional structure of the map, buildings, and an entire landscape of the game setting.

Another marketing purpose, as mentioned previously, is using the AR element for gift cards offered by different private companies and franchise. This creates an opportunity for collaboration, which as a result, benefits the company financially, and also expands their networking connections. For example, I have heard that MasterCard in Germany have the option for generically scented cards, and similarly we can add a different interactive element of AR for entertainment, or maybe the customer support information such as the phone number, email or working hours, whenever the user requires it (MacDonald, 2008).

I have gone through many ideas starting that were supposed to adapt to one of my main career goals. The main goal was to help creative art students and new artists in developing their ideas, by supporting them to overcome their financial obstacles as well as learn how to manage 
their business. But as I developed my ideas, they started revolving around students running business while they were still in school. For example, a business where students would deliver food for fellow students for a small fee, or a middleman for international students searching for an apartment and not having to pay a realtor. This application idea is just a stepping stone towards my bigger goal. I hope the experience and skills learned along the way will help me build the foundation for my company which can be the platform for my main goal, while also contribute to the community by creating innovative products and services that bring more interaction and modern ideas to the creative industry. 


\section{References}

Bhojwani, J. (2019, February 14). Greeting Cards Are Still A Thing In The Digital Age. Thanks, Millennials. Retrieved from https://www.npr.org/2019/02/14/691963430/greeting-cardsare-still-a-thing-in-the-digital-age-thanks-millennials

Jaffe, A. (1999). Packaged Sentiments. Journal of Material Culture, 4(2), 115-141. doi $10.1177 / 135918359900400201$

Javornik, A. (2016). Augmented reality: Research agenda for studying the impact of its media characteristics on consumer behaviour. Journal of Retailing and Consumer Services, 30, 252-261. doi:10.1016/j.jretconser.2016.02.004

MacDonald, J. (2008, September 22). You think your credit smells? Cards with aromas issued. Retrieved from https://www.creditcards.com/credit-card-news/that-new-cardsmell-1273.php

(2018, September 29). Greeting Cards Trends 2018. Retrieved from https:// www.pemberlyfox.com/notebook/greeting-cards-trends-2018

(2018, March 23). These AR greeting cards are more meaningful (and affordable) than plain, old boring ones. Retrieved from https://www.designboom.com/art/kineticards-chrissyeckman-augmented-reality-03-19-2018/ 